\title{
A 7-Hydroxybenzoxazinone-Containing Fluorescence Turn-On Probe for Biothiols and Its Bioimaging Applications
}

\author{
Bin Li, Datong Zhang *, Ruibing An and Yaling Zhu
}

School of Chemistry and Pharmaceutical Engineering, Qilu University of Technology (Shandong Academy of Sciences), 3501 Daxue Road, Jinan 250353, China

* Correspondence: dtzhang@qlu.edu.cn; Tel.: +86-531-89631208

Academic Editor: Evagelos Gikas

Received: 5 August 2019; Accepted: 26 August 2019; Published: 27 August 2019

\begin{abstract}
In this work, a novel 7-hydroxybenzoxazinone-based fluorescent probe (PBD) for the selective sensing of biothiols is reported. Upon treatment with biothiols, PBD shows a strong fluorescence enhancement (up to 70-fold) and a large Stokes shift (155 nm). Meanwhile, this probe exhibits high resistance to interference from other amino acids and competing species. PBD features good linearity ranges with a low detection limit of $14.5 \mathrm{nM}$ for glutathione (GSH), $17.5 \mathrm{nM}$ for cysteine (Cys), and $80.0 \mathrm{nM}$ for homocysteine (Hcy), respectively. Finally, the potential utility of this probe for biothiol sensing in living HeLa cells is demonstrated.
\end{abstract}

Keywords: fluorescence probe; biothiols; 7-hydroxy-3-phenyl-benzoxazinone; large Stokes shift; 2,4-dinitrobenzenesulfonate

\section{Introduction}

Sulfhydryl-containing amino acids, such as cysteine (Cys), glutathione (GSH), and homocysteine (Hcy), play key roles in maintaining appropriate physiological and biological processes [1-5]. Malfunction of Cys levels has been associated with hair depigmentation, slowed growth rate, liver damage, edema, and so on [6]. Elevated levels of Hcy result in cardiovascular and Alzheimer's disease $[7,8]$. GSH is the most abundant intracellular non-protein thiol and its concentration is within millimolar range. GSH deficiency is linked with cancer, liver damage, and neurodegenerative disease [9-11]. Owing to their significant roles, it is of great importance to develop rapid, simple and reliable methods for monitoring the levels of biothiols in biological systems.

Among various detection methods, fluorescent-probe-based detection has been accepted as one of the most efficient methods due to its advantages of having operational simplicity, being low cost, working under in situ real time conditions and involving no invasive bioimaging [12-16].

Great efforts have been directed to the development of fluorescent probes toward biothiols (Cys, Hcy, and GSH) [17-23]. Many probes have been constructed based on traditional fluorescent dyes, such as fluorescein [24], naphthalimide [25], coumarin [26], cyanin [27], BODIPY (boron-dipyrromethene) [23], xanthene [28], 2-(2'-hydroxyphenyl)benzothiazole [29], and dicyanomethylene-4H-pyran derivatives [30]. In spite of some sensors with good sensing performance, many of these probes still suffer from poor solubility, low sensitivity, low quantum yield, and a time-consuming detection process. Thus, it would be beneficial to develop fluorophores with a new structural skeleton. Up until now, fluorescent dyes with a 7-hydroxybenzoxazinone skeleton have received little attention [31-33]. We prepared 7-hydroxy-3-phenylbenzoxazinone (PBOH) and evaluated its optical property. PBOH exhibits strong yellow-green fluorescence and a large Stokes shift $(155 \mathrm{~nm})$. We envisioned that masking the hydroxyl group in PBOH with a 2,4-dinitrophenylsulfonyl 
group (DNBS) could generate a new fluorescent probe (PBD) for the selective detection of biothiols (Scheme 1). As they are well-known, arenesulfonates and arenesulphonamides can be readily cleaved by thiolate anions, and, therefore, the 2,4-dintrobenzenesulfonyl (DNBS) group has often been chosen as the trigger group for thiols [24,34-38]. More importantly, the DNBS group can totally quench fluorescence, thus reducing background interference, because of its strong electron-withdrawing ability. We speculate that biothiols induce cleavage of the ester bond in the DNBS-PBOH conjugates, which can release free $\mathbf{P B O H}$ and thereby restore the strong emission, thus realizing a selective fluorescence off-on recognition of biothiols. The new probe PBD indeed exhibits a significant off-on response to biothiols. The investigation of PBD suggested that it possesses a strong anti-interference ability while sensing biothiols, with a low detection limit of $14.5 \mathrm{nM}$ for GSH, $17.5 \mathrm{nM}$ for Cys, and $80.0 \mathrm{nM}$ for Hcy, respectively. In addition, PBD was successfully applied for biothiol detection in living HeLa cells.

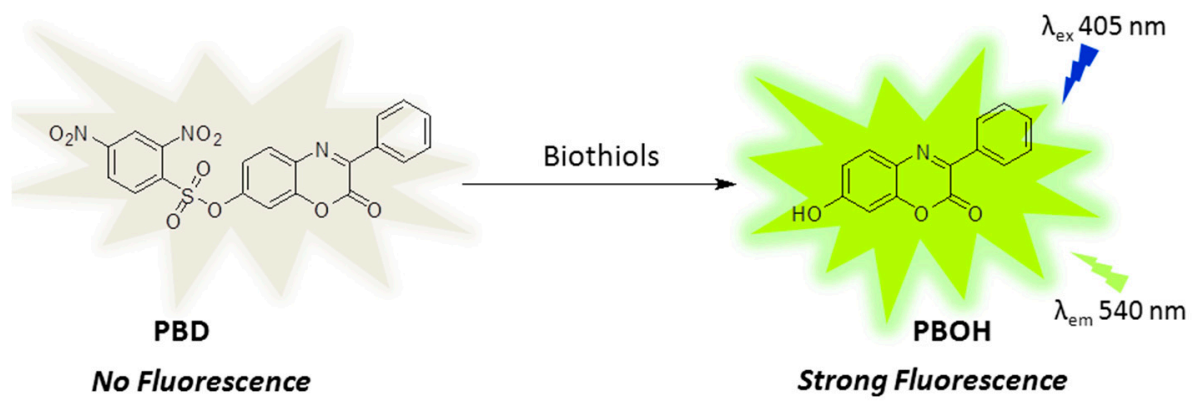

Scheme 1. Design diagram of fluorescent probe PBD (2,4-dintrobenzenesulfonate of 7-hydroxy-3-phenylbenzoxazinone) for biothiol detection.

\section{Results and Discussion}

PBOH showed strong fluorescence $(\Phi=0.60)$ with a maximum at $540 \mathrm{~nm}$ and an absorption band centered at $385 \mathrm{~nm}$ in EtOH-PBS buffer (Phosphate Buffered Saline) solution (10 mM, pH = 7.4, 4:6, $v / v)($ Stokes shift $=155 \mathrm{~nm})$. Owing to the quenching effect of the DNBS group, PBD alone exhibited extremely weak fluorescence with a low quantum yield at $540 \mathrm{~nm}(\Phi=0.011)$, and its absorption maximum was blue-shifted to $340 \mathrm{~nm}$ under the same aqueous conditions (Figure S1). As expected, upon addition of biothiols, a remarkable fluorescence intensity enhancement at $540 \mathrm{~nm}$ was observed. As such, we constructed a turn-on fluorescent probe for biothiols.

\subsection{Time-Dependence and $p H$ Effect}

The sensory effect of PBD is exemplified by its reaction with GSH. The emission intensity was recorded at different time points to evaluate the response time between PBD and various amounts of GSH. As shown in Figure 1, after addition of GSH, the fluorescence emission peak at $540 \mathrm{~nm}$ reached a plateau in about $16 \mathrm{~min}$ and maintained stability for a long time.

Kinetic analysis was conducted next. Ten equivalents of GSH, Cys, and Hcy were added into the solutions of PBD $(10 \mu \mathrm{M})$, respectively. Through monitoring the fluorescence emission at $540 \mathrm{~nm}$, the reactions were found to obey a typical pseudo-first-order and the rate constants were determined to be $0.25 \mathrm{~min}^{-1}, 0.26 \mathrm{~min}^{-1}$, and $0.20 \mathrm{~min}^{-1}$ for GSH, Cys, and Hcy respectively (Figure S5).

Furthermore, we evaluated the $\mathrm{pH}$ effect on the sensory response of PBD (Figure S3). PBD itself was inert to $\mathrm{pH}$ change, indicative of the excellent stability of the probe over a broad $\mathrm{pH}$ range. By contrast, the probe exhibited a marked fluorescence response to GSH within the $\mathrm{pH}$ range 7 to 9 , thus enabling detection of biothiols across a relatively wide $\mathrm{pH}$ range.

The following experiments of PBD were performed in EtOH-PBS buffer (10 mM, pH 7.4, 4:6, v/v) and $405 \mathrm{~nm}$ was chosen as the excitation wavelength in the fluorescent measurements. For convenience, the fluorescent intensity was recorded at $16 \mathrm{~min}$ after the addition of GSH. 


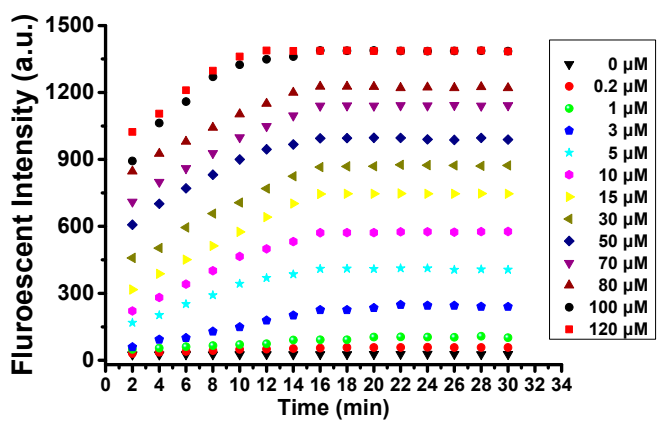

Figure 1. Time-dependent course of the interaction of PBD $(10 \mu \mathrm{M})$ with GSH in EtOH-PBS buffer (Phosphate Buffered Saline) (10 mM, pH 7.4, 4:6, v/v). Fluorescence intensity was recorded at $540 \mathrm{~nm}$ with $\lambda_{\mathrm{ex}}=405 \mathrm{~nm}$.

\subsection{Sensitivity and Selectivity Studies}

Concentration-dependent tests of PBD with GSH showed that the fluorescence intensity at $540 \mathrm{~nm}$ increased gradually with increasing GSH amounts until a stable signal was reached at $100 \mu \mathrm{M}$ (Figure 2). The fluorescence enhancement could be about 70-fold when 10 equivalents of GSH were added to the solution of PBD. As shown in Figure 2, upon treatment with GSH, the testing solution gave rise to a strong yellow-green fluorescence which is consistent with the emission spectrum of dye PBOH. A calibration plot of the signal to the GSH concentrations from $0 \mu \mathrm{M}$ to $10 \mu \mathrm{M}$ showed good linearity $\left(\mathrm{R}^{2}=0.9933\right)$, indicating that PBD can quantitatively detect GSH within this range. The detection limit of PBD toward GSH was found to be $14.5 \mathrm{nM}$ based on the 3\%/slope method [39,40], thus enabling a highly sensitive detection of GSH. We also evaluated the response effect of Cys and Hcy to PBD. Under the same conditions, PBD exhibited similar optical behavior to Cys and Hcy with the detection limits being $17.5 \mathrm{nM}$ and $80.0 \mathrm{nM}$, respectively (Figure S4).
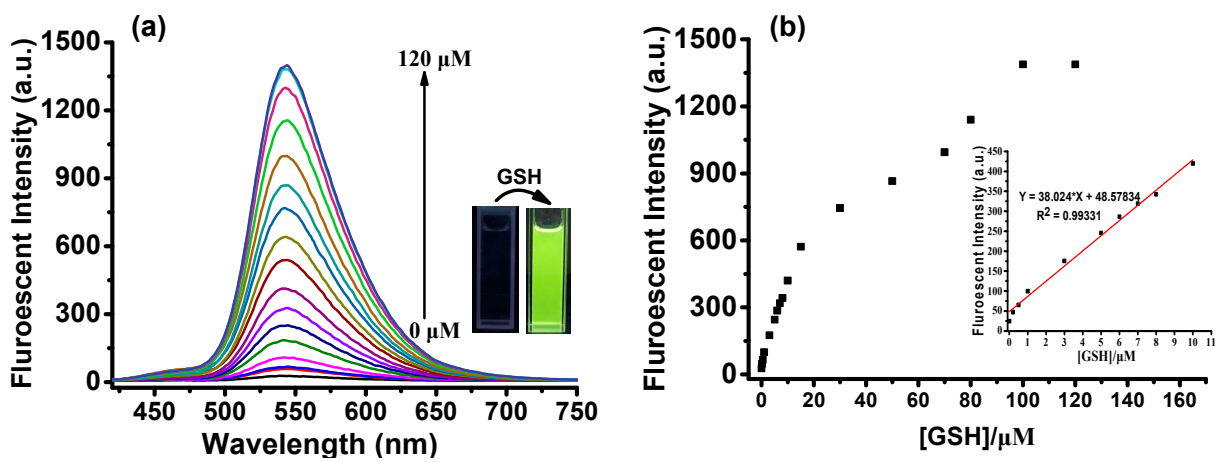

Figure 2. (a) Fluorescence response of PBD $(10 \mu \mathrm{M})$ upon the addition of GSH $(0-120 \mu \mathrm{M})$ in EtOH-PBS buffer $(10 \mathrm{mM}, \mathrm{pH} 7.4,4: 6, v / v)$. Inset: Fluorescence images of PBD $(10 \mu \mathrm{M})$ in the absence (left) and presence (right) of GSH under a $365 \mathrm{~nm}$ UV lamp. (b) Fluorescence intensity of PDB $(10 \mu \mathrm{M})$ at $540 \mathrm{~nm}$ as a function of GSH concentration (0-120 $\mu \mathrm{M})$ in EtOH-PBS buffer $(10 \mathrm{mM}, \mathrm{pH} 7.4,4: 6, v: v)$. Inset: the linear relationship between fluorescence intensity and GSH at low concentrations.

The selectivity of PBD for biothiols $(100 \mu \mathrm{M})$ was evaluated by screening its response to potential competing species $(200 \mu \mathrm{M})$, including various natural amino acids (Val, Glu, Leu, Met, Asn, Ala, His, Trp, Phe, Ser, Arg, Lys, Gln, Asp, Ile, Thr, Tyr, Pro, and Gly), sulfur species $\left(\mathrm{Na}_{2} \mathrm{~S}, \mathrm{KSCN}\right.$, $\mathrm{Na}_{2} \mathrm{SO}_{3}, \mathrm{Na}_{2} \mathrm{SO}_{4}, \mathrm{Na}_{2} \mathrm{~S}_{2} \mathrm{O}_{3}$, and $\left.\mathrm{Na}_{2} \mathrm{~S}_{2} \mathrm{O}_{4}\right)$, oxygen species $\left(\mathrm{H}_{2} \mathrm{O}_{2}\right)$, and common salts $(\mathrm{KF}, \mathrm{NaCl}, \mathrm{KBr}$, $\mathrm{KI}, \mathrm{Na}_{2} \mathrm{CO}_{3}, \mathrm{NaHCO}_{3}, \mathrm{NaNO}_{2}, \mathrm{NaNO}_{3}$, and AcONa). Figure 3 illustrates that treatment of PBD solution with 10 equivalents of GSH resulted in a 70-fold enhancement at $540 \mathrm{~nm}$. Cys gave rise to a similar fluorescence increase. Hcy induced an increment half that of GSH. High concentrations $(200 \mu \mathrm{M})$ of interfering species induced negligible changes. Following on from this, competition studies were investigated by treating PBD with GSH $(100 \mu \mathrm{M})$ in the presence of 20 equivalents of other 
analytes. As shown in Figure 4a,b, addition of GSH to the probe solution resulted in a robust signal enhancement in spite of the coexistence of competing species, demonstrating that probe PBD displays strong immunity to interference while sensing biothiols.

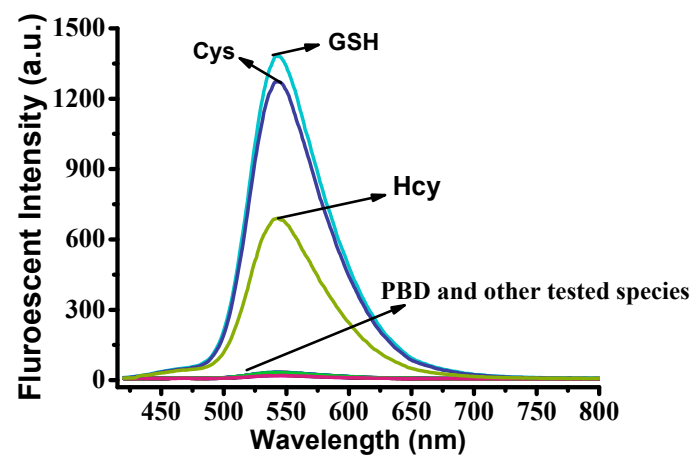

Figure 3. Fluorescence spectra of PBD $(10 \mu \mathrm{M})$ with biothiols $(100 \mu \mathrm{M})$ and various tested analytes $(200 \mu \mathrm{M}) . \lambda_{\mathrm{ex}}=405 \mathrm{~nm}$.
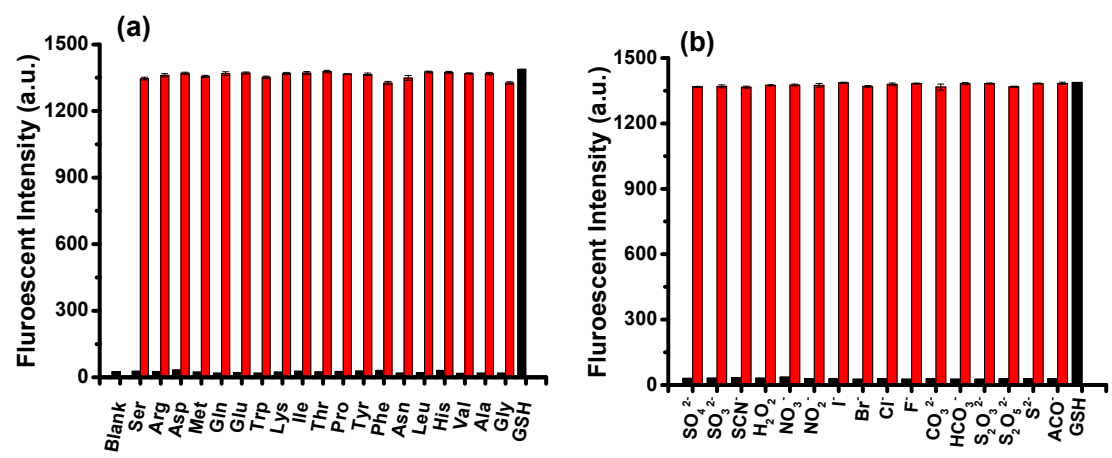

Figure 4. (a,b) Selectivity and competition of PBD $(10 \mu \mathrm{M})$ to GSH $(100 \mu \mathrm{M})$ and other analytes $(200 \mu \mathrm{M})$. Black bars represent the fluorescence intensity $(540 \mathrm{~nm})$ of a single analyte with probe PBD. Red bars represent the fluorescence intensity $(540 \mathrm{~nm}$ ) of PBD to GSH in the presence of various tested analytes. $\lambda_{\mathrm{ex}}=405 \mathrm{~nm}$.

\subsection{Sensing Mechanism Study}

The fluorescence turn-on response of PBD to biothiols may be attributed to a thiol-anion-mediated $\mathrm{S}_{\mathrm{N}} \mathrm{Ar}$ process which led to the cleavage of 2,4-dinitrophenylsulfonate (Scheme 2). A comparison of the fluorescence spectral profiles of the reaction solution and the precursor compound provides evidence for the proposed mechanism. Upon addition of GSH to non-fluorescent PBD, a turn-on fluorescent signal at $540 \mathrm{~nm}$ was observed and the emission intensity nearly reached the intensity of $\mathbf{P B O H}$. In addition, we successfully isolated the fluorescent product of the reaction by column chromatography. As expected, the ${ }^{1} \mathrm{H}-\mathrm{NMR}$ spectrum of the isolated fluorescent product is consistent with that of $\mathbf{P B O H}$. Thus, the above results confirmed that dye $\mathbf{P B O H}$ was released via the cleavage of sulfonate in PBD mediated by GSH.

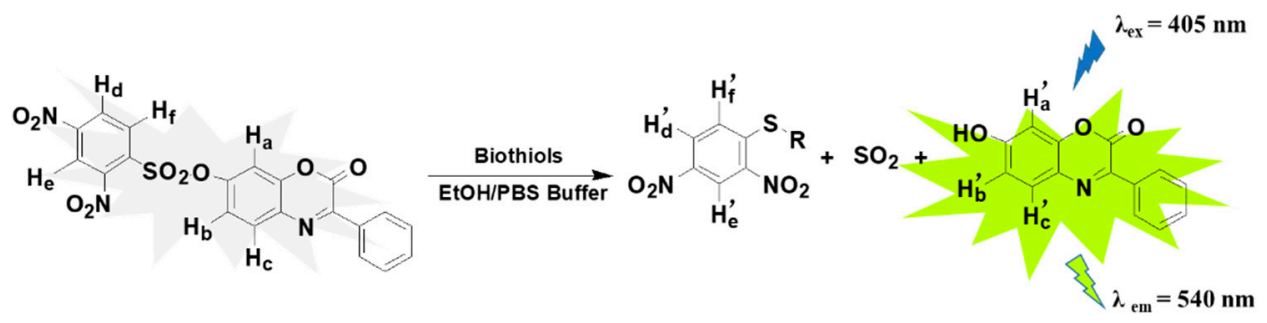

Scheme 2. Schematic sensing mechanism of PBD toward biothiols. 
To confirm the sensing mechanism, we also carried out ${ }^{1} \mathrm{H}-\mathrm{NMR}$ titration experiments to track product formation. After the addition of excessive Cys to PBD in DMSO- $d_{6} / \mathrm{D}_{2} \mathrm{O}(8 / 2, v / v)$, the signals of PBD $\left(\mathrm{H}_{\mathrm{a}}\right.$ and $\left.\mathrm{H}_{\mathrm{b}}\right)$ gradually declined. At the same time, three peaks corresponding to the protons $\left(\mathrm{H}_{\mathrm{a}}{ }^{\prime}, \mathrm{H}_{\mathrm{b}}{ }^{\prime}\right.$, and $\left.\mathrm{H}_{\mathrm{c}}{ }^{\prime}\right)$ attributable to $\mathbf{P B O H}$ began to appear, indicating that $\mathbf{P B O H}$ had been released. With the continuation of this chemical reaction, the signals of $\mathbf{P B O H}\left(\mathrm{H}_{\mathrm{a}}{ }^{\prime}, \mathrm{H}_{\mathrm{b}}{ }^{\prime}\right.$, and $\left.\mathrm{H}_{\mathrm{c}}{ }^{\prime}\right)$ gradually increased. The signals of PBD $\left(\mathrm{H}_{\mathrm{a}}\right.$ and $\left.\mathrm{H}_{\mathrm{b}}\right)$ had almost completely disappeared at $20 \mathrm{~min}$. These results demonstrate the cleavage of the DNBS group and the production of fluorophore PBOH (Figure 5).

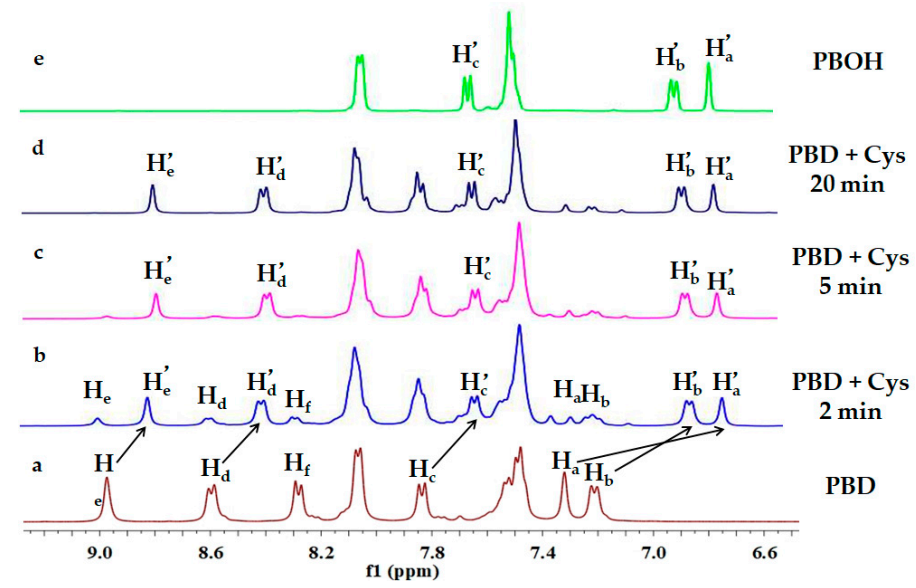

Figure 5. Partial ${ }^{1} \mathrm{H}-\mathrm{NMR}$ spectra of PBD before the addition (a) and the change after addition of Cys, $2 \mathrm{~min}(\mathbf{b}), 5 \mathrm{~min}(\mathbf{c})$, and $20 \mathrm{~min}(\mathbf{d})$, and of PBOH (e) in DMSO- $d_{6} / \mathrm{D}_{2} \mathrm{O}(8 / 2, v / v)$.

To elucidate further the off-on sensing mechanism of probe PBD towards biothiols, DFT (Density functional theory) calculations were performed. The frontier orbital diagram indicates that the LUMO energy level of DNBS $(-3.930 \mathrm{eV})$ is much lower than that of fluorophore the PBOH $(-1.021 \mathrm{eV})$ (Figure 6), which implied that the photo-induced electron transfer (PET) process can happen from the fluorophore moiety to the DNBS group. Owing to the effective fluorescence quenching effect of DNBS, PBD is essentially nonfluorescent. After removal of the DNBS group, the fluorescence is recovered.

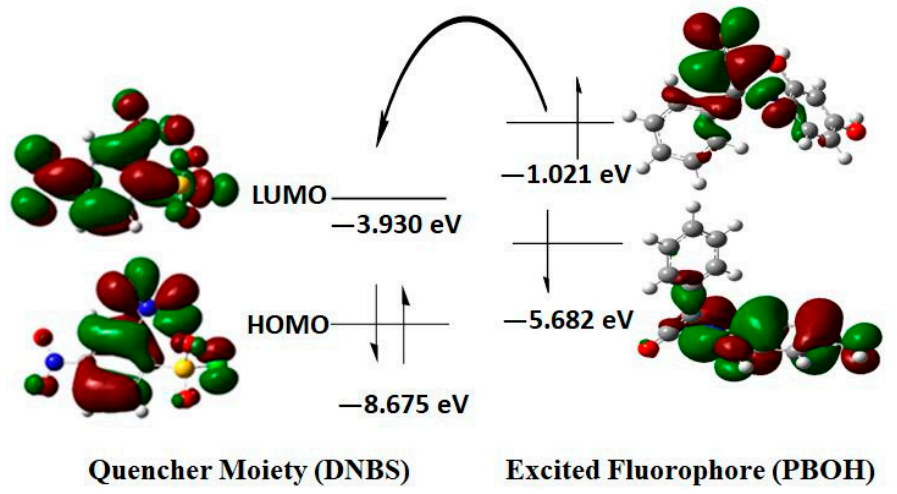

Figure 6. Frontier orbital diagrams of $\mathbf{P B O H}$ and 2,4-dinitrophenylsulfonyl (DNBS). Orbital energies were calculated using Gaussian 03 program at B3LYP/6-31 $\mathrm{g}(\mathrm{d}, \mathrm{p})$ level.

\subsection{Live Cell Imaging}

Having demonstrated its excellent responsiveness and anti-interference in sensing biothiols, we next examined whether PBD can be used to detect intracellular thiols in living cells. As shown in Figure 7, after incubating HeLa cells with PBD for $20 \mathrm{~min}$, strong yellow-green fluorescence could be observed inside the cells under excitation at $405 \mathrm{~nm}$. In the control experiments, cells were pretreated with $N$-ethylmaleimide (NEM) for $30 \mathrm{~min}$ to remove free thiols, and subsequently incubated with 
PBD for another $20 \mathrm{~min}$. After being washed with PBS buffer three times, the cells showed almost no fluorescence under a confocal fluorescence microscope. The results showed that PBD is cell-permeable and can sense intracellular biothiols in living cells.

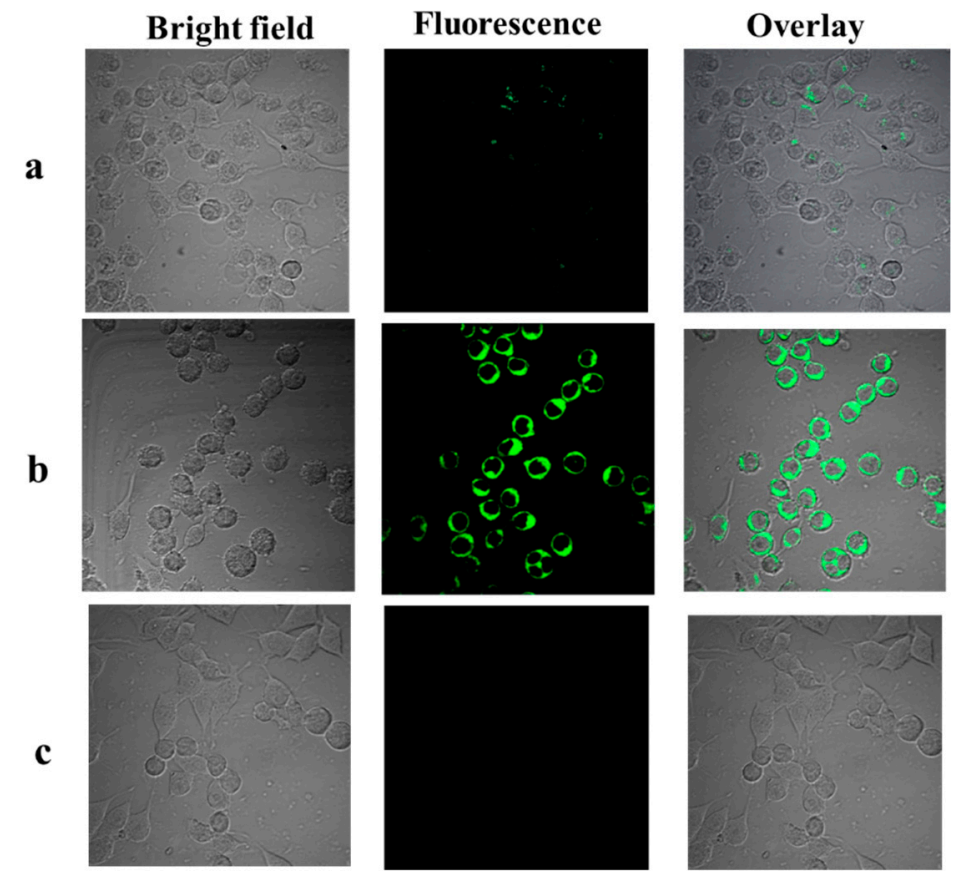

Figure 7. Confocal fluorescence images of HeLa cells. (Left) bright-field image; (middle) fluorescence image; and (right) overlayed image. (a) Cells treated with $N$-ethylmaleimide (NEM) (1 mM) for 30 min followed by incubation with PBD $(10 \mu \mathrm{M})$ for $20 \mathrm{~min}$. (b) Cells incubated with PBD $(10 \mu \mathrm{M})$ for $20 \mathrm{~min}$ at $37^{\circ} \mathrm{C}$. (c) Untreated cells.

\section{Materials and Methods}

\subsection{Materials.}

All chemicals used were of analytical grade and were obtained from commercial suppliers. TLC (Thin-layer chromatography) silica gel plates (GF-254) and silica gel (200-300 mesh) for column chromatography were obtained from Qingdao Marine Chemicals, China. Deionized water was employed throughout all experiments. ${ }^{1} \mathrm{H}-\mathrm{NMR}$ and ${ }^{13} \mathrm{C}-\mathrm{NMR}$ spectra were acquired on a Bruker AVANCE II 400 spectrometer (Bruker, Switzerland), respectively. HRMS (High Resolution Mass Spectrometry) spectra were measured with a 6510-Q-TOF spectrometer (Agilent, USA). UV-Visible absorption spectra were recorded by a TU-1901 spectrometer (Beijing, China). Fluorescent measurements were performed on a Lengguang F97Pro FL Spectrophotometer (Shanghai, China). The $\mathrm{pH}$ measurement was carried out on a Leici PHS-3C pH meter (Shanghai, China). All spectra were recorded at room temperature.

\subsection{Synthesis and Characterization of Compound Information}

The four-step synthetic route is outlined in Scheme 3. The details of the synthesis and structural characterization are shown in the Supporting Information (Figures S8-S14). 


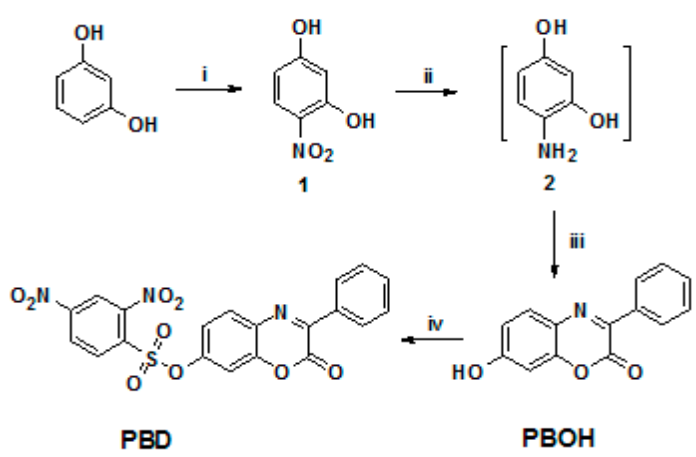

Scheme 3. Synthesis of PBD. Reagents and conditions: (i) fuming $\mathrm{HNO}_{3}, \mathrm{CHCl}_{3}$, and $\mathrm{CH}_{3} \mathrm{COOH}$, r.t.; (ii) $\mathrm{Pd} / \mathrm{C}, \mathrm{H}_{2}$, and $\mathrm{CH}_{3} \mathrm{COOCH}_{2} \mathrm{CH}_{3}$, r.t.; (iii) $\mathrm{PhCOCOOH}, \mathrm{EtOH}$, and $\mathrm{CH}_{3} \mathrm{COOH}$, r.t; (iv) 2,4-Dinitrobenzenesulfonyl chloride, $\mathrm{Et}_{3} \mathrm{~N}$, and THF, r.t.

\section{Conclusion}

In sum, we have developed a new off-on fluorescent probe PBD for biothiols by modifying a fluorescent dye 7-hydroxy-3-phenyl-benzoxazinone with a DNBS unit as a biothiol-specific recognition moiety. In response to biothiols, PBD displays significant fluorescence enhancement (up to 70-fold) and a large Stokes shift (155 nm). The probe exhibits a low detection limit as well as excellent selectivity and anti-interference ability toward biothiols over competing species. Finally, this probe has been used to sense biothiols in live HeLa cells.

Supplementary Materials: The supplementary materials are available online.

Author Contributions: B.L. and D.Z. conceived and designed experiments; B.L. performed experiments; B.L. and R.A. analyzed the data; Y.Z. conceived experiments and analyzed the data.

Funding: This study was supported by the Self-Innovation Project for Universities and Institutes of Jinan City (No. 201202035).

Conflicts of Interest: There are no conflicts of interest to declare.

\section{References}

1. Nadeau, P.J.; Charette, S.J.; Toledano, M.B.; Landry, J. Disulfide Bond-mediated Multimerization of Ask1 and Its Reduction by Thioredoxin-1 Regulate $\mathrm{H}_{2} \mathrm{O}_{2}$-induced c-Jun $\mathrm{NH}_{2}$-terminal Kinase Activation and Apoptosis. Mol. Biol. Cell. 2007, 18, 3903-3913. [CrossRef]

2. Requejo, R.; Hurd, T.R.; Costa, N.J.; Murphy, M.P. Cysteine residues exposed on protein surfaces are the dominant intramitochondrial thiol and may protect against oxidative damage. FEBS J. 2010, 277, 1465-1480. [CrossRef]

3. Ghezzi, P.; Bonetto, V.; Fratelli, M. Thiol-Disulfide Balance: From the Concept of Oxidative Stress to that of Redox Regulation. Antioxid. Redox. Signal. 2005, 7, 964-972. [CrossRef]

4. Cheng, Z.; Zhang, J.; Ballou, D.P.; Williams, C.H., Jr. Reactivity of Thioredoxin as a Protein Thiol-Disulfide Oxidoreductase. Chem. Rev. 2011, 111, 5768-5783. [CrossRef]

5. Cross, J.V.; Templeton, D.J. Thiol oxidation of cell signaling proteins: Controlling an apoptotic equilibrium. J. Cell. Biochem. 2004, 93, 104-111. [CrossRef]

6. Shahrokhian, S. Lead phthalocyanine as a selective carrier for preparation of a cysteine-selective electrode. Anal. Chem. 2001, 73, 5972-5978. [CrossRef]

7. Seshadri, S.; Beiser, A.; Selhub, J.; Jacques, P.F.; Rosenberg, I.H.; Wilson, W.F.; Wolf, P.A. Plasma homocysteine as a risk factor for dementia and Alzheimer's disease. N. Engl. J. Med. 2002, 346, 476-483. [CrossRef]

8. Refsum,H.; Ueland, P.M.; Nygard, O.; Vollset, S.E. Homocysteine and cardiovascular disease. Annu. Rev. Med. 1998, 49, 31-62. [CrossRef]

9. Lee, J.H.; Sharma, A.; Jang, J.H. Real time OFF-ON monitoring of gluthathione (GSH) in living cell. J. Incl. Phenom. Macro. 2015, 82, 117-122. [CrossRef] 
10. Aoyama, K.; Suh, S.W.; Hamby, A.M.; Liu, J.; Chan, W.Y.; Chen, Y.; Swanson, R.A. Neuronal glutathione deficiency and age-dependent neurodegeneration in the EAAC1 deficient mouse. Nat. Neurosci. 2006, 9, 119-126. [CrossRef]

11. Jung, H.S.; Chen, X.; Peng, X. Recent progress in luminescent and colorimetric chemosensors for detection of thiols. Chem. Soc. Rev. 2013, 42, 6019-6031. [CrossRef]

12. Lim, S.Y.; Hong, K.H.; Kim, D.I.; Kwon, H.; Kim, H.J. Tunable Heptamethine-Azo Dye Conjugate as an NIR Fluorescent Probe for the Selective Detection of Mitochondrial Glutathione over Cysteine and Homocysteine. J. Am. Chem. Soc. 2014, 136, 7018-7025. [CrossRef]

13. Zamfir, L.G.; Rotariu, L.; Bala, C. Sensing of sulfhydryl based compounds by a simple electrochemical approach. Sens. Actuators B Chem. 2015, 206, 65-73. [CrossRef]

14. Yin, J.; Hu, Y.; Yoon, J. Fluorescent probes and bioimaging: Alkali metals, alkaline earth metals and $\mathrm{pH}$. Chem. Soc. Rev. 2015, 44, 4619-4644. [CrossRef]

15. Farhadi, K.; Forough, M.; Pourhossein, A.; Molaei, R. Highly sensitive and selective colorimetric probe for determination of 1-cysteine in aqueous media based on $\mathrm{Ag} / \mathrm{Pd}$ bimetallic nanoparticles. Sens. Actuators B Chem. 2014, 202, 993-1001. [CrossRef]

16. Lee, M.H.; Yang, Z.; Lim, C.W.; Lee, Y.H. Disulfide-cleavage-triggered chemosensors and their biological applications. Chem. Rev. 2013, 113, 5071-5109. [CrossRef]

17. Shao, J.H.; Sun, H.; Guo, S.; Ji, J.; Zhao, W. A highly selective red-emitting FRET fluorescent molecular probe derived from BODIPY for the detection of cysteine and homocysteine: An experimental and theoretical study. Chem. Sci. 2012, 3, 1049-1061. [CrossRef]

18. Ji, W.; Ji, Y.; Jin, Q.; Tong, Q.; Tang, X. Heavy atom quenched coumarin probes for sensitive and selective detection of biothiols in living cells. Analyst. 2015, 140, 4379-4383. [CrossRef]

19. Peng, L.; Zhou, Z.; Wei, R.; Li, K.; Song, K.; Tong, A. A fluorescent probe for thiols based on aggregation-induced emission and its application in live-cell imaging. Dyes Pigment. 2014, 108, $24-31$. [CrossRef]

20. Shi, J.; Wang, Y.; Tang, X.; Liu, W.; Jiang, H.; Dou, W.; Liu, W. A colorimetric and fluorescent probe for thiols based on 1, 8-naphthalimide and its application for bioimaging. Dyes Pigment. 2014, 100, 255-260. [CrossRef]

21. Liu, J.; Sun, Y.Q.; Zhang, H.; Huo, Y.; Shi, Y.; Shi, H.; Guo, W. A carboxylic acid-functionalized coumarin-hemicyanine fluorescent dye and its application to construct a fluorescent probe for selective detection of cysteine over homocysteine and glutathione. RSC Adv. 2014, 4, 64542-64550. [CrossRef]

22. Yang, X.F.; Huang, Q.; Zhong, Y.; Li, Z.; Li, H.; Lowry, M.; Strongin, R.M. A dual emission fluorescent probe enables simultaneous detection of glutathione and cysteine/homocysteine. Chem. Sci. 2014, 5, 2177-2183. [CrossRef]

23. Niu, L.Y.; Guan, Y.S.; Chen, Y.Z.; Wu, L.Z.; Tung, C.H.; Yang, Q. BODIPY-based ratiometric fluorescent sensor for highly selective detection of glutathione over cysteine and homocysteine. J. Am. Chem. Soc. 2012, 134, 18928-18931. [CrossRef]

24. Liu, Y.C.; Xiang, K.Q.; Tian, B.Z. A fluorescein-based fluorescence probe for the fast detection of thiol. Tetra. Lett. 2016, 3, 2478-2483. [CrossRef]

25. Zhu, X.Y.; Gao, H.; Zan, W.Y.; Li, Y. A rational designed thiols fluorescence probe: The positional isomer in PET. Tetrahedron. 2016, 72, 2048-2056. [CrossRef]

26. Liao, Y.C.; Venkatesan, P.; Wei, L.F.; Wu, S.P. A coumarin-based fluorescent probe for thiols and its application in cell imaging. Sens. Actuators B Chem. 2016, 232, 732-737. [CrossRef]

27. Guo, Z.; Nam, S.; Park, S.; Yoon, J. A highly selective ratiometric near-infrared fluorescent cyanine sensor for cysteine with remarkable shift and its application in bioimaging. Chem. Sci. 2012, 3, 2760-2765. [CrossRef]

28. Rusin, O.; Luce NN, S.; Agbaria, R. Visual Detection of Cysteine and Homocysteine. J. Am. Chem. Soc. 2004, 2, 438-439. [CrossRef]

29. Yang, X.; Guo, Y.; Strongin, R.M. Conjugate Addition/Cyclization Sequence Enables Selective and Simultaneous Fluorescence Detection of Cysteine and Homocysteine. Angew. Chem. Int. Ed 2011, 50, 10690-10693. [CrossRef]

30. Lv, H.; Yang, X.F.; Zhong, Y.; Guo, Y.; Li, Z.; Li, H. Native Chemical Ligation Combined with Spirocyclization of Benzopyrylium Dyes for the Ratiometric and Selective Fluorescence Detection of Cysteine and Homocysteine. Anal. Chem. 2014, 3, 1800-1807. [CrossRef] 
31. Azuma, K.; Suzuki, S.; Uchiyama, S.; Kajiro, T.; Santa, T. A study on the thermal decomposition of KClO4and $\mathrm{NaClO} 4$ by acoustic emission thermal analysis. Photobiol. Sci. 2003, 2, 443-449. [CrossRef]

32. An, R.B.; Wei, P.; Zhang, D.T.; Su, N. A highly selective 7-hydroxy-3-methyl-benzoxazinone based fluorescent probe for instant detection of thiophenols in environmental samples. Tetra. Lett. 2016, 57, 3039-3042. [CrossRef]

33. Manna, S.; Karmakar, P.; Ali, S.S.; Guria, U.N.; Mahapatra, A.K. Michael addition-cyclization-based switch-on fluorescent chemodosimeter for Cysteine and its application in living cell imaging. New. J. Chem. 2018, 42, 4951-4958. [CrossRef]

34. Wang, J.; Zhou, C.; Zhang, J.; Zhu, X.; Liu, X.; Wang, Q.; Zhang, H. A new fluorescence turn-on probe for biothiols based on photoinduced electron transfer and its application in living cells. Spectrochim. Acta. A. 2016, 166, 31-37. [CrossRef]

35. Dai, X.; Zhang, T.; Miao, J.Y.; Zhao, B.X. A ratiometric fluorescent probe with DNBS group for biothiols in aqueous solution. Sens. Actuators B Chem. 2016, 223, 274-279. [CrossRef]

36. Dong, C.; Zhou, C.Q.; Yang, J.W.; Liao, T.C.; Chen, J.X.; Yin, C.X.; Chen, W.H. A novel 3,6-diamino-1,8-naphthalimide derivative as a highly selective fluorescent "turn-on" probe for thiols. RSC Adv. 2015, 5, 32990-32993. [CrossRef]

37. Hu, Q.H.; Yu, C.M.; Xi, X.; Wu, S.Z. A fluorescent probe for simultaneous discrimination of GSH and Cys/Hcy in human serum samples via distinctly-separated emissions with independent excitations. Biosen. Bioelectron. 2016, 81, 341-348. [CrossRef]

38. Zhang, J.J.; Yu, B.F.; Ning, L.; Zhu, X.Y.; Wang, J.X.; Chen, Z.J.; Liu, X.Y.; Yao, X.J.; Zhang, X.Y.; Zhang, H.X. A Near-Infrared Fluorescence Probe for Thiols Based on Analyte-Specific Cleavage of Carbamate and Its Application in Bioimaging. Eur. J. Org. Chem. 2015, 8, 1711-1718. [CrossRef]

39. Chen, W.; Luo, H.; Liu, X.; Foley, J.W.; Song, X. Broadly Applicable Strategy for the Fluorescence Based Detection and Differentiation of Glutathione and Cysteine/Homocysteine: Demonstration in Vitro and in Vivo. Anal. Chem. 2016, 16, 3638-3646. [CrossRef]

40. Liu, T.; Huo, F.; Yin, C.; Li, J.; Chao, J.; Zhang, Y. A triphenylamine as a fluorophore and maleimide as a bonding group selective turn-on fluorescent imaging probe for thiols. Dyes Pigment. 2016, 128, 209-214. [CrossRef]

Sample Availability: Samples of the compounds PBOH and PBD are not available from the authors.

(C) 2019 by the authors. Licensee MDPI, Basel, Switzerland. This article is an open access article distributed under the terms and conditions of the Creative Commons Attribution (CC BY) license (http://creativecommons.org/licenses/by/4.0/). 